\title{
Effect of pregnane $X$ receptor expression on drug resistance in breast cancer
}

\author{
EN-QI QIAO and HONG-JIAN YANG \\ Department of Oncological Surgery, Zhejiang Cancer Hospital, Hangzhou, Zhejiang 310022, P.R. China
}

Received February 26, 2013; Accepted December 23, 2013

DOI: $10.3892 / \mathrm{ol} .2014 .1817$

\begin{abstract}
This study was conducted to investigate the effect of increased expression of the nuclear transcription factor receptor pregnane $\mathrm{X}$ receptor (PXR) on drug resistance of breast cancer cells. Western blotting was used to detect the expression of PXR in breast carcinoma cells. The PXR agonist SR12813 was used to upregulate the expression of PXR. Semi-quantitative polymerase chain reaction was used to detect PXR gene expression in normal and cancerous breast tissues, as well as the expression levels of the drug-resistant genes multidrug resistance protein 1 (MDR1) and breast cancer resistance protein (BCRP) in breast cancer cells. A Cell Counting Kit- 8 assay was used to observe the sensitivity of the breast cancer cells to chemotherapeutic agents. Flow cytometry was used to investigate cell apoptosis. PXR expression was detected in normal and cancerous human breast tissues and in breast cancer cell lines. SR12813 treatment led to an increased expression of PXR protein and an increased expression of drug-resistant genes, MDR1 and BCRP, in MCF-7 and MDA-MB-231 cells. SR12813 pretreatment significantly increased the resistance of MDA-MB-231 cells to docetaxel. A marked increase in resistance to 4-hydroxytamoxifen was also observed in MCF-7 with SR12813 pretreatment. Additionally, we also found that pretreatment with SR12813 led to reduced apoptosis of the two cell strains induced by chemotherapeutic agents. In conclusion, PXR expression has an important effect on the sensitivity to chemotherapy of PXR-positive breast carcinoma. The inhibitory effect of PXR on cell apoptosis may contribute to the drug resistance of breast carcinoma.
\end{abstract}

\section{Introduction}

Breast cancer is the most common malignancy and the second leading cause of cancer-related mortality among females

Correspondence to: Professor Hong-Jian Yang, Department of Oncological Surgery, Zhejiang Cancer Hospital, 38 Guangji Road, Hangzhou, Zhejiang 310022, P.R. China

E-mail: qiaoenqi66@sina.com

Key words: pregnane X receptor, breast carcinoma, SR12813, drug resistance, apoptosis worldwide (1). Chemotherapy is one of the most important therapeutic approaches for breast cancer patients; however, the efficacies of drug treatments on breast cancers are often limited due to the resistance of tumor cells (2).

The pregnane $\mathrm{X}$ receptor (PXR) belongs to the nuclear hormone receptor (NR) superfamily of ligand-activated transcription factors (3), and is alternatively referred to as the steroid and xenobiotic receptor (SXR) or the pregnane-activated receptor (PAR), also termed as PXR or hPXR in humans. PXR regulates the expression of a number of downstream targeted genes, which are mostly related to the metabolism and transport of xenobiotics and associated with drug resistance in a number of cancers (4), such as cytochrome P450 (CYP450), multidrug resistance 1 (MDR1), breast cancer resistance protein (BCRP) and multidrug resistance-associated protein 2 (5-7).

In this study, we used SR12813, a potent and selective agonist of hPXR, to upregulate and activate the PXR protein in breast cancer cells, and analyzed the correlation between PXR and drug resistance in breast cancer, this study was designed to explore the formation mechanism of drug resistance of breast cancer cells and provide theoretical basis for clinical chemotherapy.

\section{Materials and methods}

Materials. Thirty-three breast carcinoma tissues and corresponding normal tissues were obtained from Jiangsu Cancer Hospital Affiliated to Nanjing Medical University (Nanjing, China). Informed consent was provided in compliance with the Declaration of Helsinki. Breast cancer cell lines, MCF-7 and MDA-MB-231, were purchased from Cell Bank of the Chinese Academy of Sciences, Shanghai Life Science Institute (Shanghai, China). Cells were cultured in Dulbecco's modified Eagle's medium (DMEM)-high glucose (Invitrogen, Carlsbad, CA, USA) supplemented with $10 \%$ fetal bovine serum (Invitrogen) and $100 \mathrm{U} / \mathrm{ml}$ penicillin-streptomycin (Invitrogen).

Reagents and instruments. hPXR (H-11) sc-48340 mouse monoclonal antibody and relevant horseradish peroxidase (HRP)-labeled secondary antibodies were purchased from Santa Cruz Biotechnology Inc., (Santa Cruz, CA, USA). $\beta$-actin AP0060 rabbit antibody was from Bioworld Technology, Inc. (Minneapolis, MN, USA). SR12813, dissolved in dimethyl sulfoxide (DMSO), and 4-hydroxytamoxifen were purchased from Sigma-Aldrich (St. Louis, MO, USA). Docetaxel was purchased from Qilu Pharmaceutical Co., Ltd (Jinan, China). The Cell 
Counting Kit-8 (CCK-8) cell proliferation-toxicity test kits were from Dojindo (Kumamoto, Japan). An RNA extraction kit, reverse transcription system and semi-quantitative PCR reagents were purchased from Takara Bio Inc. (Shiga, Japan). The total protein extraction kit was purchased from Beyotime Institute of Biotechnology (Shanghai, China). The enhanced chemiluminescence (ECL) detection system was purchased from Millipore (Billerica, MA, USA). The 7300 Real Time PCR system was from ABI (Warrington, UK). The Microplate Reader system was from Promega (Madison, WI, USA) and the BD FACSCalibur Flow Cytometer was purchased from Becton-Dickinson (New York, NY, USA).

Western blotting. Cells were directly lysed with $2 \mathrm{X}$ sodium dodecyl sulfate-polyacrylamide gel electrophoresis (SDS-PAGE) sample buffer (Beyotime Institute of Biotechnology), then boiled and sonicated. The total protein was obtained following centrifugation for $10 \mathrm{~min}$ at $15,407 \mathrm{x} \mathrm{g}$, then total protein was isolated, separated on a $10 \%$ SDS-PAGE gel and transferred to polyvinylidene difluoride (PVDF) membranes at $100 \mathrm{~V}$ for $1 \mathrm{~h}$. Then, the PVDF membranes were incubated with either anti-hPXR monoclonal antibody $\mathrm{H}-11$ (diluted to 1:800 in blocking buffer) or anti- $\beta$-actin antibody AP0060 (diluted to 1:4000 in blocking buffer) overnight at $4^{\circ} \mathrm{C}$. For staining, a goat anti-mouse HRP-labeled secondary antibody (diluted to 1:10,000 in blocking buffer) or goat anti-rabbit HRP-labeled secondary antibody (diluted to 1:2,000 in blocking buffer) were used for $1.5 \mathrm{~h}$ at room temperature. The protein bands were detected by an ECL detection system. Following normalization by the corresponding expression of $\beta$-actin, protein expression levels of PXR were determined by densitometry scans.

Semi-quantitative RT-PCR. Total RNA was extracted from cell cultures and from breast cancer and corresponding normal tissues with TRIzol ${ }^{\circledast}$ reagent (Invitrogen). Reverse transcription was performed by a Superscript T3000 Thermocycler system (Mettler-Toledo, Biometra Goettingen, Giessen, Germany). SYBR Green-based semi-quantitative PCR was used to measure relative gene expression with the following primer pairs: $\mathrm{hPXR}$ : 5'-CGA GCT CCG CAG CAT CA-3' and 5'-TGT ATG TCC TGG ATG CGC A-3'; MDR1: 5'-GTT GCT GCT TAC ATT CAG GTT TC-3' and 5'-ACC AGC CTA TCT CCT GTC GC-3'; BCRP: 5'-TCC ACT GCT GTG GCA TTA AA-3' and 5'-TGC TGA AAC ACT GGT TGG TC-3'; $\beta$-actin: 5'-TCA CCC ACA CTG TGC CCA TCT ACG A-3' and 5'-CAG CGG AAC CGC TCA TTG CCA ATG G-3'. PCR conditions were as follows: One cycle at $95^{\circ} \mathrm{C}$ for $30 \mathrm{sec}$, followed by 40 cycles of PCR amplification, each consisting of $95^{\circ} \mathrm{C}$ for $5 \mathrm{sec}$ and $60^{\circ} \mathrm{C}$ for $31 \mathrm{sec}$. The concentration of mRNA was calculated according to the standard curve and then normalized to that of $\beta$-actin. The data processing methods were according to a previous study (8).

CCK-8 assay. The cells were seeded in 96-well plates at an initial density of 8,000 cells per well. After incubation for $12 \mathrm{~h}$, cells were treated with 4-hydroxytamoxifen or docetaxel at different concentration gradients (4-hydroxytamoxifen, 0.5 , $1.0,5.0,10.0,15.0$ and $20.0 \mu \mathrm{M}$; docetaxcel, $0.05,0.1,0.2,0.4$, 0.8 and $1.6 \mu \mathrm{g} / \mathrm{ml}$ ) for 24,48 or $72 \mathrm{~h}$ directly or following a $24 \mathrm{~h}$ treatment of $0.3 \mu \mathrm{M}$ SR 12813 or $0.1 \%$ DMSO. For the
Table I. Comparison of PXR gene expression between in breast carcinoma tissues and corresponding normal tissues.

\begin{tabular}{lccccc}
\hline Group & $n$ & ${ }^{\wedge} \mathrm{CT}$ & $2^{-\Delta \Delta C \mathrm{~T}}$ & T-value & P-value \\
\hline $\mathrm{T}$ & 33 & $3.34 \pm 0.51$ & & & \\
$\mathrm{~N}$ & 33 & $6.10 \pm 0.72$ & $6.92 \pm 1.86$ & 17.979 & $<0.001$ \\
\hline
\end{tabular}

Student's t-test (two-tailed) was used to analyze the difference between the two groups. Data are presented as the mean \pm standard deviation. T, tumor tissue; N, normal breast tissue; PXR, pregnane $\mathrm{X}$ receptor.

evaluation of SR12813 cell cytotoxicity, cells were treated with SR12813 $(0.3 \mu \mathrm{M})$ or $0.1 \%$ DMSO for 24,48 or $72 \mathrm{~h}$. The cell viability was measured by CCK- 8 assay according to the manufacturer's instructions. In brief, $90 \mu \mathrm{l}$ fresh serum-free medium and $10 \mu \mathrm{l}$ CCK- 8 reagent were added into each well after decanting the old medium and culture was continued at $37^{\circ} \mathrm{C}$ for $1 \mathrm{~h}$. The optical density (OD) at $450 \mathrm{~nm}$ was measured by a microplate reader (Promega). The above steps were repeated three times and the average was calculated. The cell viability fraction (\%) was calculated as follows: $\left[\mathrm{OD}_{450 \mathrm{~nm}}\right.$

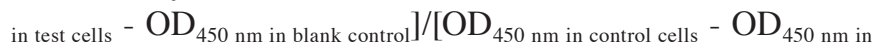
blank control]. The relative drug resistance folds were analyzed by comparison with $\mathrm{IC}_{50}$.

Flow cytometry assay of cell apoptosis. The MCF-7 and MDA-MB-231 cells were inoculated in six-well plates at a density of $2 \times 10^{5}$ cells/well. They were respectively divided into three groups, including a control group, single drug group and SR12813 $(0.3 \mu \mathrm{M})$ pretreatment group, and each group was set into three repeated wells. After $24 \mathrm{~h}$, the cells were treated respectively with complete medium containing $5 \mu \mathrm{M}$ 4-hydroxytamoxifen (MCF-7) or $0.1 \mu \mathrm{g} / \mathrm{ml}$ docetaxel (MDA-MB-231) for $24 \mathrm{~h}$. The control group cells were treated with complete medium containing the same volume of phosphate-buffered saline (PBS). Cell apoptosis was detected by BD FACSCalibur flow cytometry. The cells were detached with $0.25 \%$ trypsin and resuspended in PBS. Fluorescein isothiocyanate (FITC)-Annexin $\mathrm{V}$ and propidium iodide (PI) were added to $10^{5}$ cells, after which the cells were placed in the dark at room temperature for $15 \mathrm{~min}$ according to the manufacturer's instructions (Apoptosis Detection kit; BD Biosciences, Franklin Lakes, NJ, USA). Early apoptotic cells were stained with FITC-Annexin $\mathrm{V}(20 \mu \mathrm{g} / \mathrm{ml})$ alone, and late apoptotic cells and necrotic cells were stained with FITC-Annexin V and PI $(50 \mu \mathrm{g} / \mathrm{ml})$.

Statistical analysis. Statistical analysis was performed using SPSS 16.0 software (SPSS Inc., Chicago, IL, USA). Data are expressed as the mean \pm standard deviation. Student's t-test (two-tailed) was used to analyze the difference between two groups and one-way analysis of variance was used to analyze the difference among three groups. Data were considered to be statistically significant when $\mathrm{P} \leq 0.05$.

\section{Results}

Comparison of PXR gene expressions between in breast carcinoma tissues and corresponding normal tissues. Comparison 

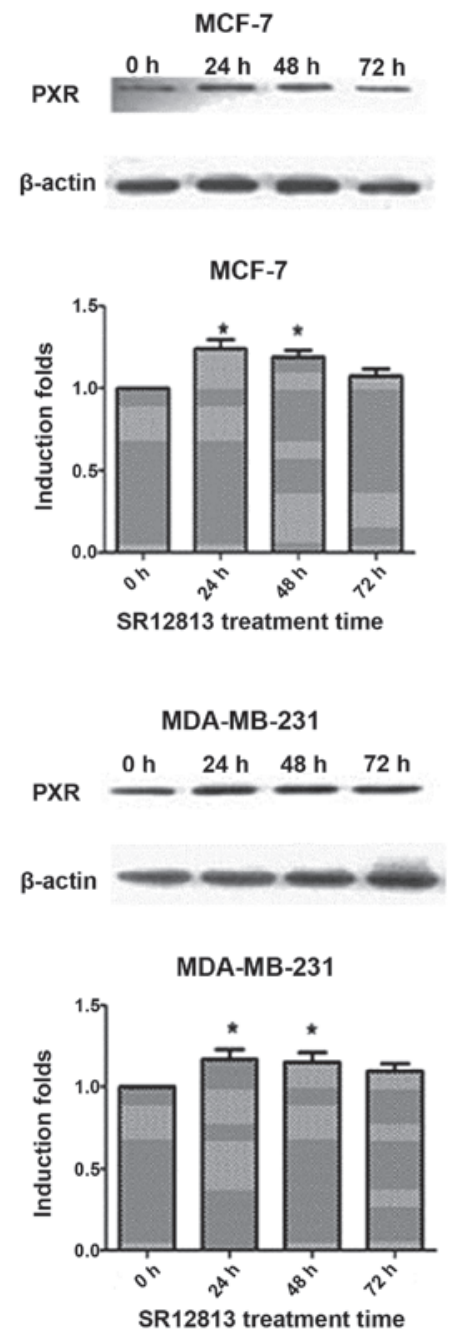

Figure 1. Changes of PXR protein levels in breast cancer cells following SR12813 treatment. After $0.3 \mu \mathrm{M}$ SR12813 treatment for $0,24,48$ or $72 \mathrm{~h}$, the PXR protein levels were evaluated by western blot assay and normalized by $\beta$-actin. Data are the mean results from three independent experiments. ${ }^{*} \mathrm{P}<0.05$, compared with the control group ( $0 \mathrm{~h}$ group). PXR, pregnane $\mathrm{X}$ receptor.

of PXR gene expression levels between breast carcinoma tissues and corresponding normal tissues is shown in Table I. The data showed that there is higher expression of PXR in breast cancer tissues. Compared with the normal breast tissues, the expression levels of PXR gene were significantly higher in breast carcinoma tissues $(\mathrm{t}=17.979, \mathrm{P}<0.001), \sim 6.92 \pm 1.86$ times according to the statistical results.

Increased PXR protein expression levels in MCF-7 and MDA-MB-231 cells following SR12813 treatment. MDA-MB-231 cells had a higher PXR expression compared with MCF-7. After treatment with $0.3 \mu \mathrm{M}$ SR 12813 for 24, 48 or $72 \mathrm{~h}$, the levels of PXR protein were increased (particularly at 24 and $48 \mathrm{~h})(\mathrm{P}<0.05)$ (Fig. 1).

Changes in MDRI and BCRP gene expression levels in breast cancer cells before and after SR12813 treatment. Compared with the control group, after treatment with $0.3 \mu \mathrm{M}$ SR12813 for $8,12,24,48$ and $72 \mathrm{~h}$, the levels of MDR1 and BCRP mRNA in MCF-7 or MDA-MB-231 cells were significantly increased by 1.5-4 times. The increased levels of MDR1 and BCRP mRNA in MCF-7 treated by SR12813 at $24 \mathrm{~h}$ were highest, $3.61 \pm 0.33$ and 3.24 \pm 0.17 times higher, respectively. The levels of MDR1 and BCRP mRNA in breast cancer cell lines MCF-7 or MDA-MB-231 before to and following SR12813 treatment were significantly different $(\mathrm{P}<0.001)$. In MDA-MB-231 cells treated with $0.3 \mu \mathrm{M}$ SR12813, the levels of MDR1 mRNA were highest at $12 \mathrm{~h}$ (up to $3.61 \pm 0.25$ times; $\mathrm{P}<0.001$ ). BCRP mRNA levels were highest at 12 and $24 \mathrm{~h}(3.28 \pm 0.24$ and $3.23 \pm 0.16$ times, respectively; $\mathrm{P}<0.001$ ) (Fig. 2). Combined with the western blot assay, the results indicate that activated PXR enhances MDR1 and BCRP gene levels in breast cancer cells.

Increased resistance of $M C F-7$ and $M D A-M B-231$ to therapeutic agents after upregulated $P X R$ expression by SR12813 treatment. The $\mathrm{IC}_{50}$ values of 4-hydroxytamoxifen to MCF-7 cells at $48 \mathrm{~h}$ were $9.81 \pm 0.49 \mu \mathrm{M}$ in the control group, $9.40 \pm 0.69 \mu \mathrm{M}$ in the DMSO treatment group and $11.57 \pm 0.83 \mu \mathrm{M}$ in the SR12813 pretreatment group. At $72 \mathrm{~h}$, these values were $8.35 \pm 0.64,8.22 \pm 0.59$ and $9.78 \pm 0.68 \mu \mathrm{M}$, respectively. The differences between the SR12813 pretreatment group and the other groups were significant $(\mathrm{P}<0.05)$ (Table II). Similarly, the $\mathrm{IC}_{50}$ values of docetaxel to MDA-MB-231 cells at $24 \mathrm{~h}$ were $0.45 \pm 0.025 \mu \mathrm{g} / \mathrm{ml}$ in the control group, $0.44 \pm 0.021 \mu \mathrm{g} / \mathrm{ml}$ in the DMSO treatment group and $0.67 \pm 0.091 \mu \mathrm{g} / \mathrm{ml}$ in the SR12813 pretreatment group. At $48 \mathrm{~h}$, these values were $0.40 \pm 0.042$, $0.39 \pm 0.025$ and $0.53 \pm 0.056 \mu \mathrm{g} / \mathrm{ml}$, and at $72 \mathrm{~h}$, these values were $0.35 \pm 0.021,0.36 \pm 0.036$ and $0.46 \pm 0.040 \mu \mathrm{g} / \mathrm{ml}$, respectively. These values in the SR12813 pretreatment group were significantly different compared with the other groups at $24 \mathrm{~h}$ $(\mathrm{P}=0.003), 48 \mathrm{~h}(\mathrm{P}=0.015)$ and $72 \mathrm{~h}(\mathrm{P}=0.025)$ (Table III).

Effect of PXR on MCF-7 and MDA-MB-231 cell apoptosis induced by therapeutic agents. Results of flow cytometric assays from control and experimental treatment groups are shown in Figs. 3 and 4. The total rates of apoptosis of cells in the control group were $5.81 \pm 0.62 \%$ (MCF-7) and $5.17 \pm 0.46 \%$ (MDA-MB-231), which were significantly increased after treatment with therapeutic agents for $24 \mathrm{~h}(\mathrm{P}<0.001)$. Compared with the single drug groups $(19.43 \pm 0.97$ and $10.27 \pm 0.80 \%$, in MCF-7 and MDA-MB-231 cells, respectively), the total rates of apoptosis of cells in the SR12813 pretreatment groups were significantly decreased $(17.26 \pm 0.40 \%, \mathrm{t}=3.571, \mathrm{P}=0.023$ and $7.69 \pm 0.54 \%, \mathrm{t}=4.647, \mathrm{P}=0.01$ in MCF-7 and MDA-MB-231 cells, respectively).

\section{Discussion}

Drug resistance of tumor cells is a complicated process with multiple factors, genes and steps. PXR is a member of the ligand-activated transcription factor superfamily called nuclear receptor subfamily 1 group I member 2 (NR1I2) whose downstream target genes are involved in the production of phase I metabolic enzymes, including CYP450 enzymes, phase II metabolic enzymes, including glucuronyltransferase (UGT) and phase III drug transporters, including P-glycoprotein (P-gp) and BCRP (6,7). Since these target genes are mostly involved in the formation of tumor MDR, PXR may be a novel master regulator of drug resistance. 
Table II. Effect of PXR on MCF-7 cell sensitivity to 4-hydroxytamoxifen.

\begin{tabular}{|c|c|c|c|c|c|c|}
\hline Group & $\mathrm{IC}_{50}$ at $48 \mathrm{~h}(\mu \mathrm{M})$ & F-value & P-value & $\mathrm{IC}_{50}$ at $72 \mathrm{~h}(\mu \mathrm{M})$ & F-value & P-value \\
\hline Control & $9.81 \pm 0.49$ & & & $8.35 \pm 0.64$ & & \\
\hline DMSO treatment & $9.40 \pm 0.69$ & & & $8.22 \pm 0.59$ & & \\
\hline SR12813 pretreatment & $11.57 \pm 0.83^{\mathrm{a}}$ & 8.529 & 0.018 & $9.78 \pm 0.68^{\mathrm{a}}$ & 16.295 & 0.045 \\
\hline
\end{tabular}

MCF-7 cells were seeded in 96-well plates at an initial density of 8,000 cells per well. After incubation for $12 \mathrm{~h}$, cells were treated with 4-hydroxytamoxifen at different concentration gradients for 24,48 or $72 \mathrm{~h}$ directly or following a $24 \mathrm{~h}$ treatment of $0.3 \mu \mathrm{M} \mathrm{SR} 12813$ or $0.1 \%$ DMSO. The viability percentages of cells with no therapeutic agents were deemed as $100 \%$. ${ }^{\mathrm{P}} \mathrm{P}<0.05$ and ${ }^{\mathrm{b}} \mathrm{P}<0.01$, assayed by one-way analysis of variance, compared with the control group or DMSO treatment group. The results are the average from three separate experiments and presented as mean \pm standard deviation. PXR, pregnane X receptor; DMSO, dimethyl sulfoxide.

Table III. Effect of PXR on MDA-MB-231 cell sensitivity to docetaxel.

\begin{tabular}{|c|c|c|c|c|c|c|c|c|c|}
\hline Group & $\begin{array}{c}\mathrm{IC}_{50} \text { at } \\
24 \mathrm{~h}(\mu \mathrm{g} / \mathrm{ml})\end{array}$ & F-value & P-value & $\begin{array}{c}\mathrm{IC}_{50} \text { at } \\
48 \mathrm{~h}(\mu \mathrm{g} / \mathrm{ml})\end{array}$ & F-value & P-value & $\begin{array}{c}\mathrm{IC}_{50} \text { at } \\
72 \mathrm{~h}(\mu \mathrm{g} / \mathrm{ml})\end{array}$ & T-value & P-value \\
\hline Control & $0.45 \pm 0.025$ & & & $0.40 \pm 0.042$ & & & $0.35 \pm 0.021$ & & \\
\hline DMSO treatment & $0.44 \pm 0.021$ & & & $0.39 \pm 0.025$ & & & $0.36 \pm 0.036$ & & \\
\hline SR12813 pretreatment & $0.67 \pm 0.091^{\mathrm{b}}$ & 16.885 & 0.003 & $0.53 \pm 0.056^{\mathrm{a}}$ & 9.079 & 0.015 & $0.46 \pm 0.040^{\mathrm{a}}$ & 7.248 & 0.025 \\
\hline
\end{tabular}

MDA-MB-231 cells were seeded in 96-well plates at an initial density of 8,000 cells per well. After incubation for $12 \mathrm{~h}$, cells were treated with docetaxel at different concentration gradients for 24,48 or $72 \mathrm{~h}$ directly or following a $24 \mathrm{~h}$ treatment of $0.3 \mu \mathrm{M} \mathrm{SR} 12813$ or $0.1 \%$ DMSO. The viability percentages of cells with no therapeutic agents were deemed as $100 \%$. ${ }^{\mathrm{P}} \mathrm{P}<0.05$ and ${ }^{\mathrm{b}} \mathrm{P}<0.01$, assayed by one-way analysis of variance, compared with the control group or DMSO treatment group. Results are the average from three separate experiments and presented as mean \pm standard deviation. PXR, pregnane X receptor; DMSO, dimethyl sulfoxide.

MCF-7

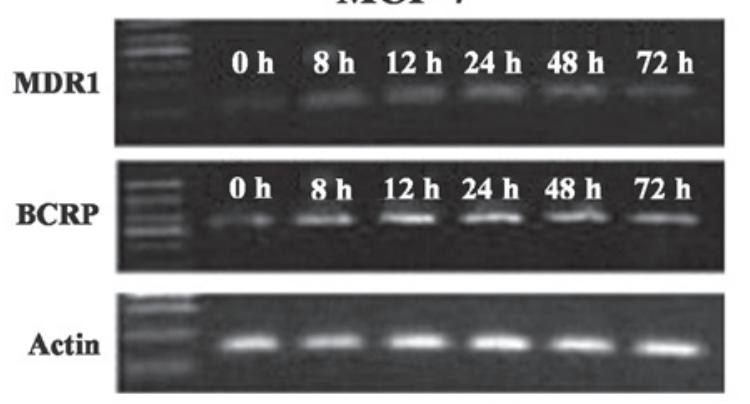

MDA-MB-231

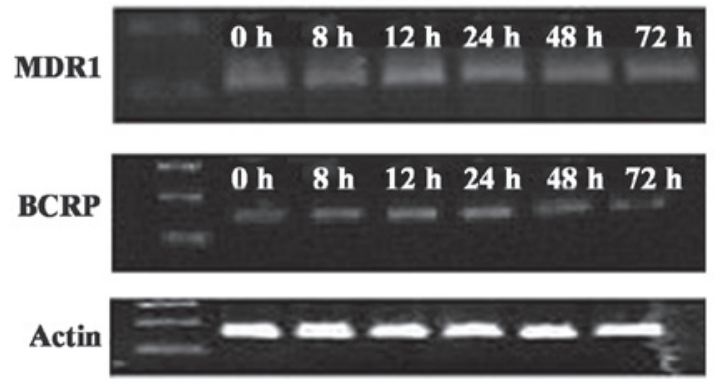

Figure 2. Activated pregnane $\mathrm{X}$ receptor enhances MDR1 and BCRP gene levels in MCF-7 and MDA-MB-231 cells. After treatment with $0.3 \mu \mathrm{M}$ SR12813 for $0,8,12,24,48$ or $72 \mathrm{~h}$, the MDR1 and BCRP gene levels were evaluated by SYBR Green-based semi-quantitative polymerase chain reaction assay and normalized by $\beta$-actin. MDR1, multidrug resistance protein 1; BCRP, breast cancer resistance protein.

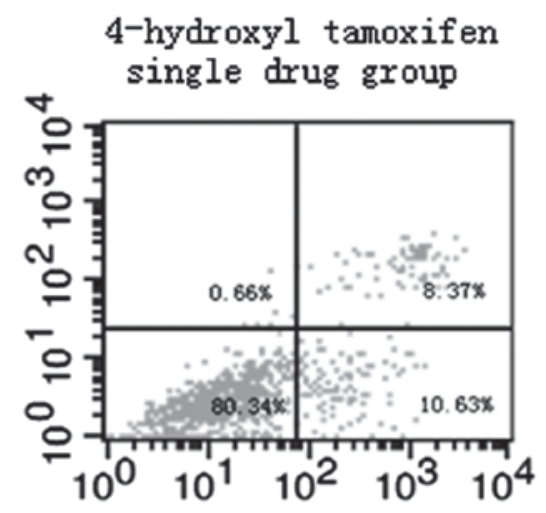

SR12813 pretreatment group

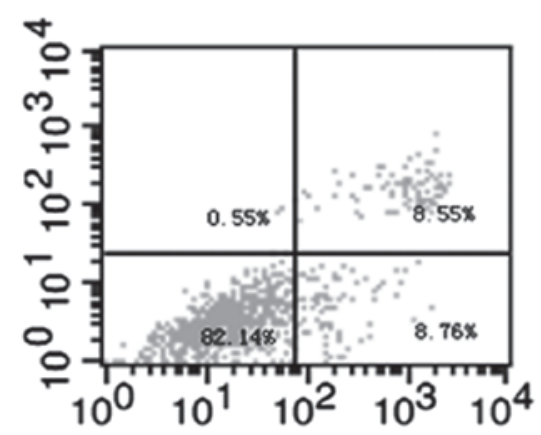

Figure 3. Results of MCF-7 apoptosis. The total rate of apoptosis in one-time independent experiment was $5.79 \%$ in the control group, $19.00 \%$ in the 4-hydroxyltamoxifen single drug group and $17.15 \%$ in the SR12813 pretreatment group. 

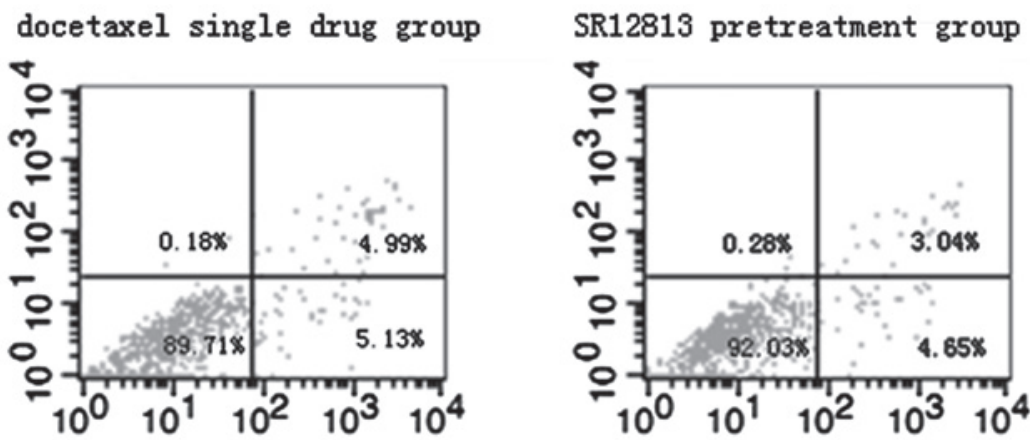

Figure 4. Results of MDA-MB-231 apoptosis. The total rate of apoptosis in a one-time independent experiment was $5.17 \%$ in the control group, $10.12 \%$ in the docetaxel single drug group and $7.69 \%$ in the SR12813 pretreatment group.

P-gp and BCRP are the main members of the ATP binding cassette $(\mathrm{ABC})$ superfamily of transporters, and are important PXR target genes (6). Their normal physiologic function is to protect the body from cytotoxicity caused by drugs or other xenobiotics. P-gp overexpression is a major cause of MDR. The protein is able to increase the outflow of a number of intracellular structurally and functionally unrelated chemotherapy drugs, including anthracyclines and taxanes, thereby reducing the efficacy (9). Navarro et al (10) reported that the combination of adriamycin and P-gp silencing formulations led to a double increase of adriamycin uptake and a significant improvement of the therapeutic effect of adriamycin in MCF-7 cells. Yuan et al (11) demonstrated there was a significant negative correlation between BCRP expression and 5-FU resistance in breast cancer cells, which may be used to optimize the chemotherapy scheme in BCRP-positive breast cancer patients. Liu et al (12) also found that P-gp and $\mathrm{BCRP}$ proteins are implicated in the formation of MDR in breast cancer and P-gp expression can be used to evaluate the efficacy of anthracycline chemotherapy in breast cancer. It is thus clear that the two proteins play an important role in breast cancer resistance mechanisms. Our study results demonstrated that treatment with SR12813 resulted in an upregulation of MDR1 and BCRP gene levels. Correspondingly, there was a significant increase in breast cancer cell resistance, which was consistent with the above findings.

A number of studies have demonstrated that PXR is involved in MDR of tumor cells. Chen et al (13) demonstrated that PXR is expressed in normal and cancerous prostate tissues and in the prostate cancer cell line PC-3. Treatment with SR12813 activated PXR and improved the level of MDR1, and increased the resistance of PC-3 cells to paclitaxel or vinblastine. The targeted knockdown of PXR reduced the resistance of PC-3 cells to paclitaxel or vinblastine. Similarly, Raynal et al (14) reported that activation of PXR increased the resistance of colorectal cancer cells to irinotecan. The increase in chemoresistance was reversed by the PXR antagonist sulforaphane. For breast cancer, Dotzlaw et al (15) first detected the expression of PXR mRNA in human breast cancer tissues by PCR amplification. Conde et al (16) further demonstrated the overexpression of PXR protein in breast cancer cells by immunohistochemistry and western blot analysis. The organic anion transporter polypeptide 1A2 (OATP1A2) is capable of mediating the cellular uptake of estrogen metabolites. Meyer zu Schwabedissen et al (17) identified that the PXR-OATP1A2 promoter interaction induced the expression of OATP1A2 in breast cancer cells, increased the uptake of the estrogen metabolite estrone 3-sulfate, and improved the estrogen effect of breast cancer. This process was also reversed by a specific antagonist of PXR, A-792611. Chen et al (18) confirmed hPXR expression in normal and cancerous human breast specimens and in breast cancer cell lines MCF-7 and MDA-MB-231. Activation of hPXR by SR12813 led to an increased expression of CYP3A4 and MDR1 in the two cell strains and improved resistance to Taxol or tamoxifen. Furthermore, knockdown of hPXR via shRNA sensitized the two cell strains to Taxol, vinblastine or tamoxifen. Jiang et al (19) demonstrated that PXR mRNA and protein were expressed in human colon cancer cell lines. The expression of PXR was increased following treatment with the PXR agonist rifampicin. PXR being activated or knocked down, accordingly increased or inhibited the cell proliferation, and enhanced or reduced the resistance of cells to the chemotherapeutic agents. However, the specific mechanism is unknown. This is one of the limited studies on PXR and tumor resistance. Our results demonstrated that treatment with SR12813 increased hPXR expression and significantly increased the expression of MDR1 and BCRP in MDA-MB-231 and MCF-7 cells, and distinctly reduced sensitivity to 4-hydroxytamoxifen or docetaxel, which was mostly consistent with previous studies. However, there were also some opposing study results. Honorat et al (20) found that PXR was also able to downregulate ABCG2 expression in PXR- and glucocorticoid receptor-positive MCF-7 cells and improved the sensitivity of MCF-7 to mitoxantrone.

Studies have demonstrated that PXR is implicated in apoptosis of tumor cells, which may be an important cause of MDR. Masuyama et al (21) confirmed that PXR overexpression led to a significant decrease in endometrial cancer cell growth inhibition and inhibited apoptosis induced by cisplatin or paclitaxel. Wang et al (22) demonstrated that in colon cancer cells, activated PXR was able to induce fibroblast growth factor 19 (FGF19)-dependent cancer cell proliferation and inhibit cell apoptosis. Moreover, the authors observed that PXR caused FGF19 activation only in the cancer cells. The present study also demonstrated that following activation and upregulated PXR expression by SR12813 treatment in MCF-7 and MDA-MB-231 cells, cell apoptosis induced by 4-hydroxytamoxifen or docetaxel was significantly inhibited. The data were consistent with the above previous findings; however, the specific mechanism requires further exploration. 
Constrastingly, Liu et al (23) demonstrated that Tanshinone IIA (Tan IIA) had marked growth inhibition effects on U-937 cells through the induction of cell apoptosis. The Tan IIA-induced apoptosis may be due to the activation of PXR, which inhibited the activity of NF- $\mathrm{KB}$ and led to the downregulation of monocyte chemoattractant protein (MCP)-1 (MCP-1/CCL2) expression. The aforementioned results indicate that PXR plays a dual role in tumor cell apoptosis.

To date, literature that discusses the correlation between PXR and breast cancer are relatively limited and the majority are related to colon cancer. In our study, we detected the expression of PXR in normal and cancerous breast tissues and in breast cancer cell lines. PXR played a significant role in MDR of breast cancer cells, and treatment with the PXR agonist SR 12813 activated and increased PXR protein expression, increased the resistance of cancer cells to chemotherapy drugs and decreased cell apoptosis. The specific mechanisms and the correlation between PXR and the development of breast cancer are yet to be explored. There are a number of opposing results among the studies discussed; therefore, further investigation is required.

\section{Acknowledgements}

This study was supported by grants from the Natural Science Foundation of China (no. 30840093), Natural Science Foundation of Zhejiang Province (no. LY12H16030), Foundation of Science Technology Department of Zhejiang Province (no. 2011C23043) and Traditional Chinese Medical Research Foundation of Zhejiang Province (no. 2011ZA016).

\section{References}

1. Jemal A, Bray F, Center MM, Ferlay J, Ward E and Forman D: Global cancer statistics. CA Cancer J Clin 61: 69-90, 2011.

2. Leonessa F and Clarke R: ATP binding cassette transporters and drug resistance in breast cancer. Endocr Relat Cancer 10: 43-73, 2003.

3. Kliewer SA, Moore JT, Wade L, et al: An orphan nuclear receptor activated by pregnanes defines a novel steroid signaling pathway. Cell 92: 73-82, 1998.

4. Minemura M, Tanimura $\mathrm{H}$ and Tabor E: Overexpression of multidrug resistance genes MDR1 and cMOAT in human hepatocellular carcinoma and hepatoblastoma cell lines. Int J Oncol 15: 559-563, 1999.

5. Tolson $\mathrm{AH}$ and Wang $\mathrm{H}$ : Regulation of drug-metabolizing enzymes by xenobiotic receptors: PXR and CAR. Adv Drug Deliv Rev 62: 1238-1249, 2010.

6. Chen T: Overcoming drug resistance by regulating nuclear receptors. Adv Drug Deliv Rev 62: 1257-1264, 2010.
7. Campa D, Butterbach K, Nieters A, et al: A comprehensive study of polymorphisms in the ABCB1, ABCC2, ABCG2, NR1I2 genes and lymphoma risk. Int J Cancer 131: 803-812, 2012 .

8. Heid CA, Stevens J, Livak KJ and Williams PM: Real time quantitative PCR. Genome Res 6: 986-994, 1996.

9. Mellor HR and Callaghan R: Resistance to chemotherapy in cancer: a complex and integrated cellular response. Pharmacology 81: 275-300, 2008.

10. Navarro G, Sawant RR, Biswas S, Essex S, Tros de Ilarduya C and Torchilin VP: P-glycoprotein silencing with siRNA delivered by DOPE-modified PEI overcomes doxorubicin resistance in breast cancer cells. Nanomedicine (Lond) 7: 65-78, 2012.

11. Yuan JH, Cheng JQ, Zhuang ZX, et al: Study on the relationship between breast cancer resistance protein expression and 5-fluorouracil resistance. Zhonghua Yu Fang Yi Xue Za Zhi 42: 506-510, 2008 (In Chinese)

12. Liu X, Chen P, Cui J and Zhang G: Expression of drug resistance related proteins in breast cancer tissues and its relationship with chemotherapy therapeutic effect. Chin J Cancer Prev Treatment 18: 1354-1357, 2011.

13. Chen Y, Nie D, Wang MT, et al: Human pregnane X receptor and resistance to chemotherapy in prostate cancer. Cancer Res 67: 10361-10367, 2007.

14. Raynal C, Evrard A, Kantar J, et al: Pregnane X receptor (PXR) expression in colorectal cancer cells restricts irinotecan chemosensitivity through enhanced SN-38 glucuronidation. Mol Cancer 9: 46, 2010.

15. Dotzlaw H, Leygue E, Watson P and Murphy LC: The human orphan receptor PXR messenger RNA is expressed in both normal and neoplastic breast tissue. Clin Cancer Res 5: 2103-2107, 1999.

16. Conde I, Lobo MV, Zamora J, et al: Human pregnane X receptor is expressed in breast carcinomas, potential heterodimers formation between hPXR and RXR-alpha. BMC Cancer 8: 174 2008.

17. Meyer zu Schwabedissen HE, Tirona RG, Yip CS, et al: Interplay between the nuclear receptor pregnane $X$ receptor and the uptake transporter organic anion transporter polypeptide $1 \mathrm{~A} 2$ selectively enhances estrogen effects in breast cancer. Cancer Res 68: 9338-9347, 2008

18. Chen Y, Tang Y, Chen S and Nie D: Regulation of drug resistance by human pregnane $\mathrm{X}$ receptor in breast cancer. Cancer Biol Ther 8: 1265-1272, 2009.

19. Jiang H, Chen W, Chen K, He J and Liang H: Roles of pregnane $\mathrm{X}$ receptor for proliferation and drug resistance in human colon cancer cells. Prog Mod Biomed 9: 2012-2015, 2009.

20. Honorat M, Mesnier A, Di Pietro A, et al: Dexamethasone down-regulates ABCG2 expression levels in breast cancer cells. Biochem Biophys Res Commun 375: 308-314, 2008.

21. Masuyama H, Nakatsukasa H, Takamoto N and Hiramatsu Y: Down-regulation of pregnane $\mathrm{X}$ receptor contributes to cell growth inhibition and apoptosis by anticancer agents in endometrial cancer cells. Mol Pharmacol 72: 1045-1053, 2007.

22. Wang H, Venkatesh M, Li H, et al: Pregnane X receptor activation induces FGF19-dependent tumor aggressiveness in humans and mice. J Clin Invest 121: 3220-3232, 2011.

23. Liu C, Li J, Wang L, et al: Analysis of tanshinone IIA induced cellular apoptosis in leukemia cells by genome-wide expression profiling. BMC Complement Altern Med 12: 5, 2012. 